\title{
ESTUDANTES NEGROS EM CURSOS DE ENGENHARIA: A REPRESENTATIVIDADE EM QUESTÃO
}

\author{
Regiane Cristina da Silva ${ }^{1}$ \\ Silvani dos Santos VAlentim ${ }^{2}$
}

\begin{abstract}
RESUMO: Este artigo trata da disparidade étnico-racial entre os estudantes dos cursos de engenharia ofertados pelo Centro Federal de Educação Tecnológica de Minas Gerais (CEFET-MG). Mediante estudo exploratório e análise dos dados, identificamos a prevalência de estudantes brancos, independentemente do campus analisado. Entre os engenheiros diplomados pela instituição no ano de 2017, esse padrão se perpetua, sinalizando a existência de um sistema de hierarquização racial, profissional e social. Nessa perspectiva, para os engenheiros negros diplomados pelo CEFET-MG e pertencentes ao grupo de renda mais baixo, ainda que atuantes em atividades inerentes à profissão, a possibilidade de mobilidade social é limitada.
\end{abstract}

Palavras-chave: Engenharia. Engenheiros negros. Raça. Desigualdades.

\section{BLACK STUDENTS IN ENGINEERING GRADUATION: REPRESENTATIVITY IN QUESTION}

\begin{abstract}
This article deals with the ethnic-racial disparity among students of engineering courses offered by the Federal Center for Technological Education of Minas Gerais (CEFET-MG), Brazil. Through exploratory study and data analysis, we identified the prevalence of white students, regardless of the analyzed campus. Among engineers graduated by the institution in 2017, this pattern is perpetuated, signaling the existence of a racial, professional, and social hierarchy system. In this perspective, for black engineers graduated by CEFET-MG and belonging to the lowest income group, even though engaged in activities inherent to the profession, the possibility of social mobility is limited.
\end{abstract}

Keywords: Engineering. Black engineers. Race. Inequalities.

\footnotetext{
Este artigo contém resultados parciais de pesquisa da dissertação "Percurso educacional de engenheiros autodeclarados negros do Centro Federal de Educação Tecnológica de Minas Gerais - CEFET-MG” ano 2017. Contou com apoio financeiro da Coordenação de Aperfeiçoamento de Pessoal de Nível Superior, protocolo n. 32020015003M7.

1.Centro Universitário Metodista Izabela Hendrix - Departamento de Engenharia - Belo Horizonte (MG) Brasil/Centro Federal de Educação Tecnológica de Minas Gerais - Departamento de Educação Tecnológica - Belo Horizonte (MG), Brasil. E-mail: regianecristina.eng@gmail.com

2.Centro Federal de Educação Tecnológica de Minas Gerais - Departamento de Educação Tecnológica - Programa de Pós-Graduação em Educação Tecnológica - Programa Especial de Formação Docente - Belo Horizonte (MG), Brasil. E-mail: silvani@cefetmg.br

Editor de Seção: Salomão Barros Ximenes

Editores convidados: Nilma Lino Gomes, José Eustáquio Brito e Paulo Vinicius Baptista da Silva
} 


\section{ESTUDIANTES NEGROS EM CURSOS DE INGENIERÍA: REPRESENTATIVIDAD IN QUESTIÓN}

RESUMEN: Este artículo trata sobre la disparidad étnico-racial entre los estudiantes de los cursos de ingeniería que ofrece el Centro Federal de Educación Tecnológica de Minas Gerais (CEFET-MG), Brasil. A través de estudio exploratorio y análisis de datos, identificamos la prevalencia de estudiantes blancos, independientemente del campus analizado. Entre los ingenieros egresados de la institución en 2017, este patrón se perpetúa, señalando la existencia de un sistema de jerarquía racial, profesional y social. En esta perspectiva, para los ingenieros negros egresados del CEFET-MG y pertenecientes al grupo de menores ingresos, aunque actuantes en actividades inherentes a la profesión, la posibilidad de movilidad social es limitada.

Palabras-clave: Ingeniería. Ingenieros negros. Raza. Desigualdades.

\section{Introdução}

A

estratificação social, segundo Carlos Hasenbalg (2005), seria produto de uma estrutura desigual de distribuição de renda, de prestígio e de privilégios entre os membros das sociedades, seguindo amparada em um sistema de hierarquização profissional, social e racial. Partindo do pressuposto de um indivíduo autodeclarado negro estar em busca de formação acadêmica em um curso de elevado prestígio social e retornos financeiros e, consequentemente, por melhores condições de vida, a tão sonhada mobilidade social por alguns grupos sociais implicaria "um movimento significativo na posição econômica, social e política de um indivíduo ou de um estrato" (STAVENHAGEN, 1977, p. 144-145).

Dada a importância do tema, o sociólogo John Goldthorpe citado por Ribeiro (2007), pioneiro nos estudos de mobilidade social, considera que as barreiras para a mobilidade relacionam-se aos fatores econômicos, sociais e culturais, bem como à necessidade de acesso às posições ocupacionais de classe, meios de produção ou títulos educacionais determinados (RIBEIRO, 2007).

Por sua vez, a estratificação educacional pode ser entendida como o campo que trata da relação entre as características de origem socioeconômica dos discentes na entrada do sistema educacional e as características observáveis na saída, após a diplomação, bem como dos mecanismos através dos quais entrada e saída se relacionam (SILVA, 2003; PICANÇO; MORAIS, 2016). Essas relações podem estabelecer-se a partir do tipo de instituição superior escolhida pelo sujeito ou grupo familiar (pública ou privada) e pela qualidade creditada ao curso, assim como pelo período (diurno, noturno) em que o curso é ofertado nas instituições (RIBEIRO; SCHLEGEL, 2015).

A desigualdade de acesso propende a persistir nos cursos mais seletivos, como as engenharias, considerando que a educação escolar oferecida pelo poder público

[...] não é suficiente para garantir o sucesso do aluno no processo seletivo para os cursos e instituições de Ensino Superior de maior prestígio. Faz-se necessário, portanto, complementar a educação escolar com outros cursos como de língua estrangeira moderna, informática, curso preparatório para o processo seletivo e ainda com a aquisição de outros bens culturais. Assim, resta aos pais financiar essa complementação da educação escolar. Os custos dessa complementação são altos, e viáveis apenas para os pais com maior poder aquisitivo, que, dentro do contexto brasileiro, não chegam a 10\% do quantitativo de famílias com renda familiar 
acima de 20 salários mínimos. Desse modo, trata-se da minoria da população estudantil brasileira que se encontra matriculada no Ensino Médio ministrado pela iniciativa privada e em cursos complementares (BORGES; CARNIELLI, 2005, p. 17).

O que se pretende aqui é a identificação do público negro estudante de engenharia e do profissional negro recém-formado, privilegiado ou não economicamente, bem como das especificidades da sua formação, com preparação suficiente para alcance profissional elevado ou apenas estudantes persistentes e ávidos pela formação em engenharia. Falar em privilégio considerando o percurso educacional de jovens negros parece um tanto contraditório, podendo ser sentido como penetrar num universo simbólico, destoante da maioria da população negra brasileira, e um tanto incomum entre os temas abordados na multiplicidade de pesquisas sobre estudantes negros no Ensino Superior.

\section{CEFET-MG e a Educação Profissional e Tecnológica}

O Centro Federal de Educação Tecnológica de Minas Gerais (CEFET-MG), como centro de referência em educação tecnológica, oferta sólida formação aos seus discentes, da educação básica até o doutoramento. Nessa instituição, estudantes de diferentes níveis educacionais têm a oportunidade de usufruir de um valoroso conhecimento nacionalmente reconhecido, em um ambiente que proporciona o compartilhamento de suas experiências e pesquisas, sempre orientados por um corpo docente apto e atuante nas diversas camadas de ensino. Ao longo dos seus 110 anos, o CEFET-MG mantém-se como instituição de excelência no âmbito da educação tecnológica, ofertando cursos em níveis médio, médio técnico, graduação e pós-graduações lato e stricto sensu. Em seu centésimo aniversário, o CEFET-MG já dispunha de 71 cursos distribuídos nos mais diferentes níveis, todos ofertados com o atributo qualificador de uma instituição pública federal. Anualmente, são ofertadas, em média, mil vagas para os cursos de nível superior. Por sua vez, os cursos de engenharia correspondem a 75\% das matrículas (FUNDAÇÃO CEFET-MG, 2018).

$\mathrm{O}$ centro federal assume um caráter elitista pelo elevado prestígio social e acadêmico devidamente reconhecido ao longo de sua história. Em 2011, o CEFET-MG reforçou sua relevância no âmbito nacional, ocupando o segundo e o terceiro lugares do ranking na avaliação das dez instituições mais disputadas pelo Sistema de Seleção Unificada (SiSU).

A educação tecnológica proporciona uma formação dilatada aos estudantes, amparada numa perspectiva voltada para os aspectos humanísticos, ainda que acudida na perspectiva positivista e racional, em que o conhecimento tem como bases a ciência e a tecnologia. Grinspun (2002) apresenta reflexões sobre a importância da educação tecnológica como um processo educacional que deve levar em consideração a interdependência da tecnologia, da educação e das relações sociais, mantendo sempre a responsabilidade ética e social como instituição formadora.

Neste sentido, poderia assim indagar como uma instigação pedagógica: para que serve, então, uma educação tecnológica? Arrisco uma resposta: para formar um indivíduo, na sua qualidade de pessoa humana, mais crítico e consciente para fazer a história do seu tempo com possibilidade de construir novas tecnologias, fazer uso da crítica e da reflexão sobre a utilização de forma mais precisa e humana, e ter as condições de, convivendo com o outro, participando da sociedade em que vive transformar essa sociedade em termos mais justos e humanos (GRINSPUN, 2002, p. 29). 
A consolidação do CEFET-MG como estabelecimento pautado na educação tecnológica, vem a ser o resultado de uma política institucional secular que abrange magistralmente distintas áreas do conhecimento e que compreende a importância da capacitação constante do corpo docente para a preservação de um elevado padrão educacional, ofertado gratuitamente a toda a população, em especial ao povo mineiro. Apresentamos na Tabela 1 a distribuição dos cursos de graduação nos campi do estado de Minas Gerais.

Tabela 1. Distribuição dos cursos do CEFET-MG

\begin{tabular}{cc}
\hline Cidade & Curso \\
\hline Araxá & Engenharia de Minas \\
& Engenharia de Automação Industrial \\
\hline & Engenharia de Produção Civil \\
& Engenharia Mecânica \\
Engenharia Elétrica \\
Engenharia de Transportes \\
Engenharia de Materiais \\
Eelo Horizonte & Engenharia Ambiental e Sanitária \\
& Administração \\
& Letras \\
& Formação de Docentes \\
& Química Tecnológica \\
\hline Curvelo & Engenharia Civil \\
\hline Divinópolis & Engenharia Mecatrônica \\
& Design de Moda \\
\hline Leopoldina & Engenharia de Controle e Automação \\
\hline Nepomuceno & Engenharia Elétrica \\
\hline Varginha & Engenharia Civil da Computação \\
\hline Timóteo &
\end{tabular}

Fonte: Elaboração própria, 2020. ${ }^{1}$

Os campi do CEFET-MG encontram-se distribuídos em nove cidades do estado de Minas Gerais. Foram relacionadas na Tabela 1 as oito cidades em que há oferta de cursos de nível superior, sendo excluído apenas o campus Contagem, que, atualmente, oferta os cursos técnicos de Informática, Eletroeletrônica e Controle Ambiental.

Na pesquisa divulgada pela Secretaria de Política Estudantil (SPE), atual Diretoria de Desenvolvimento Estudantil (DDE) do CEFET-MG, mediante dados do ano de 2010, foi apresentado o perfil dos estudantes em comparação ao perfil dos alunos de institutos federais no âmbito nacional. Tal pesquisa representa uma pequena parcela do estudo encomendado pela Associação Nacional dos Dirigentes da Instituições Federais de Ensino Superior (Andifes) ao Fórum Nacional de Pró-reitores da Assuntos Comunitários e Estudantis (Fonaprace) (CEFET-MG, 2013).

Nessa conjuntura, foram entrevistados alunos do CEFET-MG dos cursos de Engenharia Mecânica, Engenharia Industrial Elétrica, Engenharia de Produção Civil, Engenharia de Computação, Engenharia Ambiental, Engenharia de Materiais e Administração, todos do campus Belo Horizonte; Engenharia Mecatrônica, de Divinópolis; Engenharia de Controle e Automação, de Leopoldina; Engenharia de Computação, de Timóteo; e Engenharia de Automação Industrial, de Araxá. Também foram entrevistados alunos dos cursos de Tecnologia em Normalização e Qualidade Industrial, Tecnologia em Radiologia, Química Tecnológica e do Programa Especial de Formação Pedagógica de Docentes. A matéria, publicada 
inicialmente em 2013, descrevia o perfil do alunado de graduação pelo mapeamento das vidas cultural, econômica e social dos discentes.

Os dados mostram que, em relação à faixa etária, a maioria dos estudantes cefetianos $(57,88 \%)$ se encontrava entre os 20 e 24 anos. No que diz respeito ao gênero, a presença era majoritariamente masculina (72,55\%), com estudantes solteiros e sem filhos (90\%). Entre o meio de transporte utilizado pelos alunos para chegarem ao centro federal, a porcentagem era de 29,35\% para veículo próprio - seja carro ou motocicleta - contra $21,62 \%$ no âmbito nacional. O número de graduandos que passaram pelo ensino técnico cefetiano e seguiram no centro federal para cursar a graduação era mais que o dobro da média nacional: 19,84\% contra 8,24\%. Quanto à renda mensal das famílias,

os números estão bem dispersos, sendo que a maior parte [da renda dos discentes] do CEFET-MG está entre 2 e 6 salários mínimos (46,06\%). Nacionalmente, a concentração acontece de 1 a 4 salários mínimos (49,98\%). No CEFET-MG, 27,72\% dos discentes têm renda mensal familiar acima de 10 salários mínimos. No país, esse número é de 16,72\% (CEFET-MG, 2013, p. 1).

O estudo elaborado pela SPE evidencia a representação racial dos discentes do CEFET-MG segundo o parâmetro de cor/raça estipulado pelo IBGE. A Tabela 2 demonstra a proporção étnico-racial baseada na autodeclaração dos discentes.

Tabela 2. Cor/raça autodeclarada dos estudantes de institutos federais - ano 2010

\begin{tabular}{ccc}
\hline Raça/cor & CEFET-MG & Brasil \\
\hline Brancos & $63,04 \%$ & $53,93 \%$ \\
\hline Pardos & $28,80 \%$ & $32,08 \%$ \\
\hline Pretos & $5,43 \%$ & $8,72 \%$ \\
\hline Indígenas & $0,82 \%$ & $0,93 \%$ \\
\hline Amarelos & $1,90 \%$ & $3,06 \%$ \\
\hline
\end{tabular}

Fonte: Elaboração própria, ${ }^{1} 2020$.

A presença significativa de estudantes autodeclarados da raça/cor branca nos cursos de nível superior supera a média nacional em aproximadamente 10\%. A composição negra, ou seja, de pardos e pretos, em contrapartida, é menor se comparada à média brasileira: $34,23 \%$ dos discentes cefetianos contra $40,80 \%$ dos discentes em âmbito nacional.

Categorias significativas para o decurso deste trabalho foram expostas na Tabela 3. De acordo com a tabela, o critério utilizado para a definição de classe econômica relaciona-se ao poder de compra das famílias urbanas, em relação ao qual o que está em jogo é a posse de bens materiais, como aparelhos domésticos, eletroeletrônicos, a presença de empregada doméstica no lar, a situação da moradia, automóveis, grau de instrução do chefe da família, entre outros.

Tabela 3. Classe econômica

\begin{tabular}{ccc}
\hline Classe & CEFET-MG & Brasil \\
\hline Classe A & $19,29 \%$ & $15,25 \%$ \\
\hline Classe B & $56,25 \%$ & $41,07 \%$ \\
\hline Classe C & $21,74 \%$ & $33,60 \%$ \\
\hline Classe D & $2,72 \%$ & $9,60 \%$ \\
\hline Classe E & $0 \%$ & $0,48 \%$ \\
\hline
\end{tabular}

Fonte: Elaboração própria, ${ }^{1} 2020$. 
Os dados apresentados sinalizam a presença de um público classes A e B $(75,54 \%)$, concentrando famílias com maior acesso a bens materiais, o que destoa até mesmo dos parâmetros nacionais evidenciados na pesquisa, de 56,32\%. Impera o consenso de que os critérios para a determinação de um grupo social devem abranger tanto as particularidades de renda, profissão e disposição de recursos materiais quanto aspectos mais simbólicos, como estilo de vida, nível de escolaridade e suas práticas culturais. Contudo, Flávia Fialho destaca a importância do "padrão de consumo" na definição do grupo "classe média" (2012), de modo que

[...] ao se estudar a classe média, [seja] preciso lembrar a associação entre classes médias e consumo na literatura, pois esse consumo de padrão acima do popular é um recurso central na formação da identidade dessa classe. Assim, se lembrarmos que o consumo diferenciado se relaciona diretamente com a posição na ocupação, tem-se, por consequência, também o nível de rendimento como fator importante para identificar a classe média (GUERRA et al., 2006, p. 17).

Entendendo a forte segmentação que abrange a classe média brasileira, Quadros (2003) avalia a existência de uma classe média segmentada em três estratos, considerando a ocupação do sujeito. Buscando exemplificar os estratos, no grupo "classe média baixa" estariam os auxiliares de escritório, vendedores, professores da educação básica. Integrantes da "classe média média" seriam os trabalhadores de carreiras técnicas e demais profissionais com ocupações nas esferas pública e privada. Por último, os engenheiros, gerentes, administradores e outros profissionais com formação superior integrariam a "classe média alta".

Para o desenvolvimento deste artigo, consideramos que, quando nos referimos às camadas de maior renda da população brasileira, trazendo um conceito de classe social, não nos limitamos apenas à identificação econômica, mas também ao status social. Cabe aqui utilizarmos a noção de classe de Bourdieu (1998), o qual define classe por meio da inclusão de valores, gestos, gostos e estilos de vida que convergem para a formação de grupos homogêneos de sociabilidade com posições sociais parecidas.

\section{Ensino Superior Brasileiro}

No que se refere à ampliação do Ensino Superior brasileiro nas últimas décadas, Comin e Barbosa (2011) apontam para um novo público entre os graduandos, destacando-se a formação de uma quantidade maior de mulheres, jovens e pessoas negras, com percentual elevado de universitários já atuantes no mercado de trabalho (acima de 65\%).

Antes mesmo de ser utilizado em grande escala por instituições federais como forma de acesso às Instituições de Ensino Superior (IES) e ao (SiSU), o Exame Nacional do Ensino Médio (Enem) vem sendo progressivamente ampliado desde o ano de 2004, quando passou a ser empregado na seleção das bolsas universitárias em instituições privadas do Programa Universidade para Todos (ProUni). Almeida disserta sobre a origem do modelo de ensino universitário que predomina no país: um tipo peculiar de "modelo empresarial, com origem e impulso datados da década de 1970, por meio de incentivos públicos dados às instituições particulares, dentre os quais se destacam a não cobrança de impostos e o crédito educativo", o atual Fundo de Financiamento Estudantil (FIES), constituído inicialmente em 1976 (ALMEIDA, 2014, p. 96).

É fato que a maioria dos estudantes negros brasileiros segue como integrante de famílias de baixa renda e egressos(as) de escola pública (IBGE, 2010). Sem maiores opções para a realização do Ensino Superior e impulsionados pelo Enem, esse grupo étnico passou a ter chances reais de ultrapassar as barreiras de competição do vestibular em IES públicas ou privadas. Diferentemente dos vestibulares com a cobrança 
dos conteúdos escolares, o Enem passou a avaliar o candidato pelas habilidades e competências humanas para a resolução de problemas, não dependendo agora de que o aluno dominasse o conhecimento formal (ANDRIOLA, 2011). O resultado se deu de forma instantânea, segundo Almeida (2017), de modo que frações da sociedade de baixa renda e da classe média baixa lograram sucesso com a admissão aos espaços acadêmicos, conseguindo quebrar a barreira de acesso a universidades, centros universitários e faculdades.

Os dados do Resumo Técnico do Censo da Educação Superior apresentam a quantidade de IES em território brasileiro. A Tabela 4 expõe o número dessas instituições de acordo com sua categoria administrativa e sua organização acadêmica.

Tabela 4. Número de Instituições de Educação Superior por categoria administrativa - 2018

\begin{tabular}{|c|c|c|c|c|c|c|}
\hline \multirow{2}{*}{ Organização acadêmica } & \multirow{2}{*}{ Total } & \multicolumn{4}{|c|}{ Pública } & \multirow{2}{*}{ Privada } \\
\hline & & Subtotal & Federal & Estadual & Municipal & \\
\hline Total & 2537 & 299 & 110 & 128 & 61 & 2238 \\
\hline Universidade & 199 & 107 & 63 & 40 & 4 & 92 \\
\hline Centro Universitário & 230 & 13 & 2 & 2 & 9 & 217 \\
\hline Faculdade & 2068 & 139 & 5 & 86 & 48 & 1929 \\
\hline IF e CEFET & 40 & 40 & 40 & n.a. & n.a. & n.a. \\
\hline
\end{tabular}

Nota: n.a. = "não se aplica"; Fonte: Tabela elaborada pela Deep/Inep, 2018. Adaptada pelas autoras, 2020.

Diante desses números, as IES privadas passaram a ser um destino muito atrativo, ocasionando, em certo momento, um decréscimo nos níveis de inscritos para os cursos de duas conceituadas universidades brasileiras: a Universidade de São Paulo (USP) e a Universidade de Campinas (Unicamp) (ALMEIDA, 2017). Diante desse novo cenário, um estudante de baixa renda, por exemplo, constantemente constrangido pelas dificuldades econômicas e competitivas em busca de uma vaga nas universidades públicas, "passou a ter, ainda que sob muitos obstáculos a superar, potencialidades e alternativas reais de inserção no segmento privado de Ensino Superior por meio do ProUni” (ALMEIDA, 2017, p. 95).

O acesso às IES pelo ProUni se dá por dois tipos de bolsas: integral e parcial. Para a primeira opção, o estudante necessita comprovar renda familiar per capita de até um salário mínimo e meio. No caso de a renda familiar per capita ser superior a um salário mínimo e meio, não ultrapassando o valor de três salários mínimos, o candidato poderá disputar uma bolsa parcial. As bolsas parciais admitem que o valor restante seja financiado pelo (FIES). Para além da condição socioeconômica, o ProUni também preconiza a reserva de vagas para pessoas autodeclaradas negras, indígenas e com deficiência.

Toda essa movimentação vem acompanhando uma mudança generalizada em torno da distribuição e da autodeclaração racial da população, especialmente na primeira década do século XXI, tendo o público negro alcançado, no final da década, índices em torno de 50,9\%, conforme dados do Censo Demográfico (IBGE, 2010). O ponto a salientar, de acordo com Almeida (2017), seria justamente sobre as mudanças ocorridas no interior do sistema privado no que concerne ao atendimento de uma parcela de jovens negros, bolsistas do ProUni e de baixa renda. Sobre o perfil de estudantes negros e negras contemplados em instituições privadas como bolsistas do ProUni, Sotero identificou dois grupos distintos: "aqueles com prévia experiência em vestibulares em universidades públicas [sem terem logrado êxito] e os que tiveram na seleção do programa a primeira tentativa de ingresso no Ensino Superior" (2009, p. 93). Então, qual o perfil dos estudantes negros que lograram êxito no acesso às IES públicas? 


\section{A Identificação do Perfil dos Estudantes das IES}

Nos últimos anos, a identificação do perfil dos estudantes das IES tem movimentado as associações nacionais. A Andifes tem se proposto identificar o perfil dos estudantes nas Instituições Federais de Ensino Superior (IFES) por meio de pesquisas com os discentes.

Em sua quarta edição, intitulada Perfil socioeconômico e cultural dos estudantes da graduação das Instituições Federais de Ensino Superior, do ano de 2014, a pesquisa apresentou o perfil dos estudantes a partir de dados socioeconômicos, origem escolar e pertencimento racial autodeclarado, entre outros aspectos. Inicialmente, os dados evidenciaram que a faixa etária dominante entre os discentes de IFES estaria entre 18 a 24 anos (66,28\% do público). A despeito da renda familiar per capita dos discentes,

[...] nota-se que os graduandos com renda mensal familiar per capita média mais alta são os dos cursos de Engenharia ( $\mathrm{R} \$ 1.085,5)$ e Ciências Sociais Aplicadas ( $\mathrm{R} \$ 1.080,7)$, seguidos do grupo das Ciências da Saúde ( $\mathrm{R} \$ 870)$ e Ciências Exatas e da Terra ( $\$$ \$ 867). Em terceiro lugar vem a renda dos graduandos das Ciências Humanas ( $\mathrm{R} \$ 817,4)$ e Linguística, Letras e Artes ( $\mathrm{R} \$ 815,8$ ); em quarto lugar em termos de renda estão os graduandos das Ciências Agrárias ( $\mathrm{R} \$ 705,3)$ e, por último, o das Ciências Biológicas (R\$641,3) (ANDIFES, 2016, p. 16).

A renda familiar per capita entre os alunos admitidos entre 2011 a 2013 apresentou média de $\mathrm{R} \$ 921,00$. No entanto, os alunos de instituições federais admitidos em cursos de graduação nos anos anteriores a 2009 tinham como estimativa mais elevada de renda média per capita algo em torno de R\$1.386,10. As desigualdades, porém, persistem, à sombra seja do rendimento, seja do gênero: $65 \%$ dos discentes se declararam do sexo masculino e $35 \%$ do sexo feminino. Em relação à cor/etnia, a distribuição dos graduandos na região Sudeste apresenta índices de 53,5\% para os autodeclarados brancos; 30,2\% de autodeclarados pardos; $9,13 \%$ de pretos quilombolas e não quilombolas; $2 \%$ de amarelos e $0,27 \%$ de indígenas. Os sem declaração contabilizaram 4,8\% (ANDIFES, 2016). Outra constatação importante aferida pela pesquisa está relacionada à origem escolar do público pesquisado, cuja

[...] maioria $(60,16 \%)$ fez toda sua trajetória da educação básica integralmente na rede pública, destacando que quanto mais recente for o ingresso, maiores são os valores alcançados, sendo que aqueles(as) que ingressaram após 2013 já correspondem a 64,53\% de estudantes com vida escolar exclusiva em instituições públicas. Todavia, há discrepâncias relevantes a serem destacadas, pois a clivagem racial demonstra uma relação direta entre cor da pele e origem escolar, comprovadas pelo quantitativo de $68 \%$ de pardos, $75,6 \%$ de pretos não quilombolas, $78,3 \%$ de pretos quilombolas, 66,9\% de indígenas não aldeados e de 85,7\% de indígenas aldeados cuja origem escolar está vinculada absolutamente às escolas públicas (ANDIFES, 2016, p. 246-247).

Almeida (2017) considera que haja indícios de uma elevada dificuldade em se apurar dados oficiais de estudantes e egressos, principalmente no que se refere a autodeclaração étnico-racial, condição socioeconômica e distribuição das vagas nos centros e universidades, refreando a chance de se ter uma visão mais acurada do acesso da população negra brasileira na educação superior. Diante dessas ponderações e conscientes das limitações, propomos a captura de dados que identifiquem o perfil do estudante cefetiano, visando ao acesso à educação superior de pessoas autodeclaradas negras nos cursos de engenharia. 


\section{Metodologia}

O comportamento social humano, como relata Babbie (2003), pode ser submetido à rigidez processual de uma pesquisa científica, sem que apresente diferenças na investigação das Ciências Sociais para as outras ciências. A distribuição da população deste estudo seguiu os métodos de pesquisa da Ciência Social, nos quais o cientista social procura nas regularidades do comportamento dos indivíduos (re)descobrir as correlações existentes.

Neste estudo exploratório, a unidade primária de amostra foram pessoas: engenheiros cefetianos e a identificação dos cursos frequentados. Com a classificação racial, alcançou-se a População a ser analisada. Realizada a agregação da unidade primária de amostra em uma categoria específica, que, neste caso, é a autodeclaração étnico-racial, o(a) engenheiro(a) cefetiano(a) negro(a) constituiu a unidade secundária da amostragem. A partir dessa segunda unidade amostral, obtivemos os elementos considerados fundamentais para a seleção, já que, nessa etapa, foram selecionados especificamente, os(as) egressos(as) do ano de 2017: a unidade final de amostra (BABBIE, 2003).

Para compreensão mais apurada da composição racial dos estudantes de engenharia do centro federal, partimos da totalidade do corpo discente a fim de verificar o percentual de estudantes autodeclarados pretos e pardos. Durante a análise documental, contamos com relatórios oficiais, banco de dados dos(as) alunos(as) egressos(as) do CEFET-MG e da Comissão Permanente de Vestibular (COPEVE), para a extração de informações sobre os cursos de Engenharia de Automação Industrial, Engenharia de Minas, Engenharia Ambiental e Sanitária, Engenharia da Computação, Engenharia de Materiais, Engenharia de Transportes, Engenharia Elétrica, Engenharia Mecânica, Engenharia de Produção Civil, Engenharia Civil, Engenharia de Controle e Automação e Engenharia Mecatrônica. Quanto ao tempo mínimo de conclusão dos cursos de engenharia, as graduações seguem previstas, geralmente, no prazo de dez semestres. No CEFET-MG, entretanto, os cursos de Engenharia de Automação Industrial, Engenharia Elétrica (campus Nepomuceno) e Engenharia Civil (campus Curvelo) possuem duração de onze semestres e a Engenharia Metalúrgica, de doze semestres. Sobre os cursos citados com duração de onze e doze semestres não foram encontrados(as) egressos(as) no período analisado.

As informações utilizadas neste artigo compõem a base de dados da dissertação em curso, cujo projeto de pesquisa foi aprovado pelo Sistema CEP/CONEP (Projeto CAAE: 165652 19.0.0000.8507). O presente trabalho foi realizado com apoio financeiro da Coordenação de Aperfeiçoamento de Pessoal de Nível Superior (CAPES) e da Coordenadoria de Gênero, Raça, Ações Afirmativas e Identidades (CGRAI), com permissão de acesso ao banco de dados da instituição, o que proporcionou a seleção e a coleta de dados dos estudantes com matrícula ativa no ano de 2017. Essa seleção se deu no ano de 2019, entre os meses de julho e agosto.

Os estudantes selecionados foram agrupados em quatro categorias: curso de graduação em engenharia, autodeclaração racial, campus frequentado e endereço eletrônico. Os dados seguem expostos na Tabela 5 .

A média aritmética racial dos estudantes revela uma possível estagnação dos índices raciais, em comparação com a pesquisa divulgada pela SPE, com dados referentes ao ano de 2010: estudantes autodeclarados brancos, na ocasião, eram 63\%; pardos e pretos, respectivamente, $28,8 \%$ e $5,43 \%$. 
Tabela 5. Composição étnico-racial dos estudantes de engenharia do CEFET-MG - ano 2017

\begin{tabular}{|c|c|c|c|c|c|c|c|c|}
\hline \multirow{3}{*}{$\begin{array}{l}\text { Campus } \\
\text { Araxá }\end{array}$} & \multirow{3}{*}{$\begin{array}{l}\text { Curso } \\
\text { aria de Automação } \\
\text { Industrial }\end{array}$} & \multirow{3}{*}{$\begin{array}{c}\begin{array}{c}\text { N. de } \\
\text { registros }\end{array} \\
176\end{array}$} & \multicolumn{4}{|c|}{ Negro } & \multirow{2}{*}{\multicolumn{2}{|c|}{ Branco }} \\
\hline & & & \multicolumn{2}{|c|}{ Pardo } & \multicolumn{2}{|c|}{ Preto } & & \\
\hline & & & 53 & $30,11 \%$ & 14 & $7,95 \%$ & 109 & $61,94 \%$ \\
\hline Araxá & Engenharia de Minas & 170 & 53 & $31,18 \%$ & 11 & $6,47 \%$ & 106 & $62,35 \%$ \\
\hline \multirow{7}{*}{ Belo Horizonte } & Ambiental e Sanitária & 404 & 112 & $27,72 \%$ & 30 & $7,43 \%$ & 262 & $64,85 \%$ \\
\hline & Engenharia da Computação & 404 & 126 & $31,19 \%$ & 18 & $4,46 \%$ & 260 & $64,35 \%$ \\
\hline & Engenharia de Materiais & 376 & 112 & $29,79 \%$ & 26 & $6,91 \%$ & 238 & $63,30 \%$ \\
\hline & Engenharia de Transportes & 211 & 92 & $43,60 \%$ & 17 & $8,06 \%$ & 102 & $48,34 \%$ \\
\hline & Engenharia Elétrica & 446 & 132 & $29,60 \%$ & 22 & $4,93 \%$ & 292 & $65,47 \%$ \\
\hline & Engenharia Mecânica & 463 & 129 & $27,86 \%$ & 20 & $4,32 \%$ & 314 & $67,82 \%$ \\
\hline & Engenharia Produção Civil & 435 & 135 & $31,03 \%$ & 17 & $3,91 \%$ & 283 & $65,06 \%$ \\
\hline Timóteo & Engenharia da Computação & 216 & 85 & $39,35 \%$ & 12 & $5,56 \%$ & 119 & $55,09 \%$ \\
\hline Nepomuceno & Engenharia Elétrica & 185 & 60 & $32,43 \%$ & 11 & $5,95 \%$ & 114 & $61,62 \%$ \\
\hline Curvelo & Engenharia Civil & 349 & 164 & $46,99 \%$ & 33 & $9,46 \%$ & 152 & $43,55 \%$ \\
\hline Varginha & Engenharia Civil & 220 & 47 & $21,36 \%$ & 12 & $5,45 \%$ & 161 & $73,19 \%$ \\
\hline Leopoldina & $\begin{array}{c}\text { Engenharia de Controle e } \\
\text { Automação }\end{array}$ & 339 & 80 & $23,60 \%$ & 21 & $6,19 \%$ & 238 & $70,21 \%$ \\
\hline Divinópolis & Engenharia Mecatrônica & 213 & 57 & $26,76 \%$ & 10 & $4,69 \%$ & 146 & $68,55 \%$ \\
\hline \multicolumn{2}{|c|}{ Total de alunos matriculados - ano 2017} & 4.607 & \multicolumn{2}{|c|}{1.437} & \multicolumn{2}{|c|}{274} & \multicolumn{2}{|c|}{2.896} \\
\hline \multicolumn{3}{|c|}{ Média aritmética racial } & \multicolumn{2}{|c|}{$31,50 \%$} & \multicolumn{2}{|c|}{$6,12 \%$} & \multicolumn{2}{|c|}{$62,38 \%$} \\
\hline
\end{tabular}

Fonte: Elaboração própria, ${ }^{2} 2020$.

\section{Resultados}

\section{A Seleção dos Estudantes Cefetianos}

A autodeclaração racial apontou a presença de pessoas autodeclaradas brancas, amarelas, indígenas e negras. No entanto, as categorias amarelo e indígena foram desconsideradas nas análises por apresentarem índices inferiores a $1 \%$. Seguidamente a seleção dos cursos, agrupamento racial e quantificação de egressos, foi estipulada a concentração média de engenheiros conforme cor/raça: brancos(as) (77\%), pardos(as) (19,9\%) e pretos(as) (3,1\%). Na seleção, foram quantificados(as) 161 engenheiros(as) diplomados(as) entre o primeiro e o segundo semestres de 2017 nos campi "cefetianos" localizados nas cidades de Araxá, Belo Horizonte, Timóteo, Curvelo, Nepomuceno, Varginha, Leopoldina e Divinópolis. 
Tabela 6. Composição étnico-racial dos(as) egressos(as) de engenharia do CEFET MG - ano 2017

\begin{tabular}{|c|c|c|c|c|c|c|c|c|}
\hline \multirow{2}{*}{ Campus } & \multirow{2}{*}{ Curso } & \multirow{2}{*}{$\begin{array}{l}\text { N. de } \\
\text { registros }\end{array}$} & \multicolumn{4}{|c|}{ Negro } & \multirow{2}{*}{\multicolumn{2}{|c|}{ Branco }} \\
\hline & & & & ardo & & reto & & \\
\hline \multirow{2}{*}{ Araxá } & $\begin{array}{c}\text { Engenharia de Automação } \\
\text { Industrial }\end{array}$ & 13 & 4 & $30,77 \%$ & 0 & 0 & 9 & $69,23 \%$ \\
\hline & Engenharia de Minas & 15 & 4 & $26,67 \%$ & 1 & $6,67 \%$ & 10 & $66,67 \%$ \\
\hline \multirow{7}{*}{ Belo Horizonte } & $\begin{array}{c}\text { Engenharia Ambiental e } \\
\text { Sanitária }\end{array}$ & 9 & 1 & $11,11 \%$ & 0 & 0 & 8 & $88,89 \%$ \\
\hline & Engenharia da Computação & 6 & 0 & $0 \%$ & 0 & 0 & 6 & $100,00 \%$ \\
\hline & Engenharia de Materiais & 11 & 2 & $18,18 \%$ & 0 & 0 & 9 & $81,82 \%$ \\
\hline & Engenharia de Transportes & 0 & 0 & $0 \%$ & 0 & 0 & 0 & $0,00 \%$ \\
\hline & Engenharia Elétrica & 22 & 4 & $18,18 \%$ & 0 & 0 & 18 & $81,82 \%$ \\
\hline & Engenharia Mecânica & 13 & 1 & $7,69 \%$ & 0 & 0 & 12 & $92,31 \%$ \\
\hline & Engenharia de Produção Civil & 24 & 5 & $20,83 \%$ & 0 & 0 & 19 & $79,17 \%$ \\
\hline Timóteo & Engenharia da Computação & 12 & 5 & $41,67 \%$ & 2 & $16,67 \%$ & 5 & $41,67 \%$ \\
\hline Nepomuceno & Engenharia Elétrica & 0 & 0 & $0 \%$ & 0 & 0 & 0 & $0,00 \%$ \\
\hline Curvelo & Engenharia Civil & 5 & 0 & $0 \%$ & 0 & 0 & 5 & $100,00 \%$ \\
\hline Varginha & Engenharia Civil & 0 & 0 & $0 \%$ & 0 & 0 & 0 & $0,00 \%$ \\
\hline Leopoldina & $\begin{array}{c}\text { Engenharia de Controle e } \\
\text { Automação }\end{array}$ & 19 & 4 & $21,05 \%$ & 2 & $10,53 \%$ & 13 & $68,42 \%$ \\
\hline Divinópolis & Engenharia Mecatrônica & 12 & 2 & $16,67 \%$ & 0 & 0 & 10 & $83,33 \%$ \\
\hline & Total & 161 & & 32 & & 5 & & 124 \\
\hline
\end{tabular}

Fonte: Elaboração própria, ${ }^{2} 2020$.

Procuramos aferir, com maior fidedignidade, a quantidade de engenheiros brancos e não brancos diplomados nos campi cefetianos especificamente no ano de 2017, conforme apresentado na Tabela 6. Em Divinópolis, o curso de Engenharia Mecatrônica apresentou índice de diplomação de estudantes autodeclarados(as) da cor/raça branca superior a 83\%. Em Belo Horizonte, esse percentual atinge índices superiores a 79\% e, em alguns cursos, como Engenharia Ambiental e Sanitária, e Engenharia da Computação, 88\% e 100\%, respectivamente. Nos campi Araxá e Leopoldina, esses valores chegam próximo a 70\%. Não foram identificadas diplomações de estudantes nos campi de Nepomuceno e Varginha, em 2017, nos cursos aptos à formação de engenheiros(as).

A exceção quanto à soberania branca entre os(as) engenheiros(as) diplomados(as) em 2017 se deu no campus Timóteo: cinco autodeclarados pardos e dois autodeclarados pretos entre os doze discentes diplomados em engenharia, correspondendo a 58,34\% de egressos(as) negros(as). Encontramos, dessa forma, o público-alvo deste estudo: uma amostra de 37 engenheiros(as) negros(as), sendo 32 autodeclarados(as) pardos(as) e cinco pretos(as). 
Na sequência, um questionário on-line foi elaborado e enviado por correio eletrônico para os(as) egressos(as) a fim de obter a confirmação dos dados pessoais dos 37 engenheiros(as) autodeclarados(as) negros(as) (somados os(as) pretos(as) e pardos(as)). O questionário contou com questões fechadas e abertas e uma breve introdução no início de cada subseção tratou do conteúdo e da finalidade esperada.

As perguntas do questionário perpassavam autodeclaração racial, curso frequentado, atuação profissional, nível educacional, rendimento atual, local onde reside, estado civil, origem escolar, contemplação ou não das Políticas Públicas de Ação Afirmativa durante o processo de admissão, sexo, contato telefônico e idade. Dos 37 questionários encaminhados por endereço eletrônico, obtivemos respostas de oito egressos(as) entre os meses de julho e agosto de 2019. Por fim, as respostas foram tabuladas utilizando-se o software Microsoft Excel 2010 e permanecem expostas no Tabela 7.

Tabela 7. Tabulação parcial das respostas ao questionário on-line

\begin{tabular}{|c|c|c|c|c|c|c|c|c|c|}
\hline & or $/ \mathbf{r}$ & & $\begin{array}{l}\text { Ano de } \\
\text { adm. }\end{array}$ & $\begin{array}{c}\text { Origem } \\
\text { escolar }\end{array}$ & $\begin{array}{c}\text { Renda } \\
\text { (per capita/adm.) } \\
\text { em salários }\end{array}$ & Formação/ocu & pação atual & $\begin{array}{l}\text { Renda atual } \\
\text { em salários } \\
\text { mínimos }\end{array}$ & $\begin{array}{c}\text { Nível } \\
\text { educacional }\end{array}$ \\
\hline & A & Preto & 2009 & Federal & $<1,5$ & $\begin{array}{l}\text { Engenharia } \\
\text { Elétrica }\end{array}$ & Aposentado & $<1$ & Graduação \\
\hline Grupo & $\mathrm{B}$ & Pardo & 2013 & Estadual & $<1,5$ & $\begin{array}{l}\text { Engenharia da } \\
\text { Computação }\end{array}$ & $\begin{array}{l}\text { Analista de } \\
\text { Sistemas }\end{array}$ & 1 a 2 & Graduação \\
\hline I & $\mathrm{C}$ & Pardo & 2013 & Privada & 1,5 a 2,5 & $\begin{array}{l}\text { Engenharia de } \\
\text { Produção Civil }\end{array}$ & $\begin{array}{c}\text { Engenheiro } \\
\text { Projetista }\end{array}$ & 1 a 2 & Graduação \\
\hline & $\mathrm{D}$ & Pardo & 2010 & Estadual & 1,5 a 2,5 & $\begin{array}{l}\text { Engenharia da } \\
\text { Computação }\end{array}$ & $\begin{array}{l}\text { Analista de } \\
\text { Sistemas }\end{array}$ & 3 a 4 & Graduação \\
\hline & & $\begin{array}{l}\text { Pardo/ } \\
\text { Branco }\end{array}$ & 2010 & Estadual & 3 a 5 & $\begin{array}{c}\text { Engenharia } \\
\text { de Minas }\end{array}$ & Professor & $<1$ & $\begin{array}{l}\text { Especialização } \\
\text { lato Sensu }\end{array}$ \\
\hline Grupo & $\mathrm{F}$ & Pardo & 2012 & Federal & 5 a 10 & $\begin{array}{r}\text { Engenharia } \\
\text { de Materiais }\end{array}$ & Estudante & 1 a 2 & $\begin{array}{l}\text { Especialização } \\
\text { stricto sensu } \\
\text { - Mestrado }\end{array}$ \\
\hline II & G & Pardo & 2013 & Privada & 10 a 20 & $\begin{array}{l}\text { Engenharia } \\
\text { Elétrica }\end{array}$ & $\begin{array}{l}\text { Engenheiro } \\
\text { Projetista }\end{array}$ & 5 a 7 & Graduação \\
\hline & $\mathrm{H}$ & Pardo & 2011 & Federal & 5 a 10 & $\begin{array}{l}\text { Engenharia } \\
\text { de Automação } \\
\text { Industrial }\end{array}$ & $\begin{array}{l}\text { Piloto } \\
\text { Comercial }\end{array}$ & $>8$ & Graduação \\
\hline
\end{tabular}

Fonte: Elaboração própria, ${ }^{2} 2019$.

Encontramos, na resposta ao questionário, uma mudança na autopercepção racial de um dos entrevistados. O egresso do campus Araxá, diplomado em Engenharia de Minas, havia se autodeclarado pardo durante a admissão ao CEFET-MG, em 2010. À época da resposta ao questionário, em 2019, autodeclarou-se da cor/raça branca.

Nicodemos reflete que a construção identitária do sujeito não permanece na inércia, "uma vez que sofre transformações a partir do processo de socialização que os sujeitos culturais estabelecem durante a vida e em vários espaços, dentre eles a escola" (2011, p. 31). A identificação racial brasileira, reconhecida por Munanga (1996), deve se manifestar a partir do reconhecimento da ancestralidade africana, da sua representatividade como descendentes de povos soberanos, dotados de um conhecimento inigualável e de uma cultura valorosa. Para o autor, reconhecer-se pertencente a esse grupo étnico-racial está para além da recognição da cor da pele. 
No que tange ao rendimento, os engenheiros do Grupo I apresentaram renda familiar per capita menor quando comparada à renda do Grupo II. Interessante notar que a renda atual acompanha o rendimento declarado pelo egresso no ano de admissão ao CEFET-MG: aqueles que dispunham de rendimento per capita menor que um salário mínimo e meio (<1,5 s.m.) declararam receber, atualmente, proventos dentro dessa faixa salarial (Egressos A e B). Assim como os engenheiros com renda de até dois salários mínimos e meio $(<2,5$ s.m.) manifestaram rendimento de um a dois salários mínimos (Egresso C) e três a quatro salários mínimos (Egresso D).

Nesse entendimento, podemos aferir comportamento similar presente no Grupo II. Os Egressos G e $\mathrm{H}$, aqueles com renda per capita familiar de cinco a vinte salário mínimos ( 5 a 20 s.m.) tendem à manutenção do padrão de rendimento declarado nos anos de 2011 e 2013: o Egresso G revela possuir rendimento de cinco a sete salários mínimos; e o Egresso $\mathrm{H}$, proventos superiores a oito salários mínimos. A exceção desse comportamento se deu entre os engenheiros que deram sequência aos estudos em cursos de especialização lato e stricto sensu.

Dado o panorama étnico-racial e econômico dos(as) egressos(as) cefetianos(as) e a formação de dois grupos distintos, Grupo I e Grupo II, justificados pela desproporcionalidade de rendimento, a renda declarada durante a admissão dos(as) egressos(as) se revelou variável significativa de estratificação econômica e reprodução social.

Entretanto, como explicar o fato de que pessoas negras diplomadas em cursos de elevado prestígio social - ainda que viessem a desenvolver funções pertinentes à área de formação - recebessem salários tão desiguais? Como explicar uma possível reprodução da desigualdade de renda entre indivíduos de um mesmo grupo étnico-racial desprestigiado? Na busca por resposta, trazemos Osório:

[a] tese defendida é a de que a persistência da desigualdade racial de renda [...] ocorre porque, nos processos de mobilidade que levam à definição da renda, a origem social tem um grande peso, ao qual se somam os efeitos da discriminação racial. A origem social é o principal fator de reprodução da desigualdade, mas a persistência só é possível pelo complemento da discriminação (2009, p. 315).

Nesse entendimento, o rendimento das famílias seria um importante elemento a ser considerado na avaliação da reprodução da desigualdade. Investigando dados mais recentes sobre a classificação racial e o rendimento dos estudantes de graduação, encontramos na Plataforma Nilo Peçanha (PNP) elementos sobre a renda familiar autodeclarada pelos discentes do CEFET-MG. A PNP realiza estudos sobre a Rede Federal de Educação Profissional, Científica e Tecnológica (SETEC-MEC) com o objetivo de reunir dados relativos aos corpos discente, docente, técnico-administrativo e financeiros da rede federal.

Em sua edição mais recente, publicada em 17 de junho de 2020, com aporte interno do Ministério da Educação, foram levantadas informações quanto a cursos, titulação, número de matrículas, modalidade de ensino, cidades e federação das unidades. Diante das informações, foi possível selecionar a instituição CEFET-MG, as cidades onde estão instalados os campi, bem como as graduações destinadas à formação de bacharéis em engenharias.

No que tange à classificação racial dos estudantes matriculados nas oito unidades do CEFET-MG no estado (Araxá, Belo Horizonte, Curvelo, Divinópolis, Leopoldina, Nepomuceno, Timóteo e Varginha), foram contabilizadas o total de 5.626 matrículas, sendo 47,55\% autodeclarados da cor/raça branca; 41,21\% da cor/ raça parda; 7,54\% da cor/raça preta e da amarela 3,66\%. A cor/raça indígena alcançou o percentual de 0,04\%.

Na Tabela 8, seguem expostos dados sobre a cor/raça autodeclarada dos estudantes do CEFET-MG e o rendimento familiar (faixa de renda per capita familiar do aluno, declarada na PNP pela instituição). 
Tabela 8. Classificação racial $\times$ renda familiar (entre os declarados) estudantes de engenharia do CEFET MG - ano 2019

\begin{tabular}{cccccccc}
\hline Renda Familiar & Amarela & Branca & Indígena & Parda & Preta & Não declarada & Total geral \\
\hline Total geral & 185 & 2403 & 2 & 2083 & 381 & 572 & 5626 \\
\hline $0<\mathrm{RFP}<=0,5$ & 30 & 240 & 0 & 300 & 81 & 50 & 701 \\
\hline $0,5<\mathrm{RFP}<=1,0$ & 54 & 465 & 1 & 524 & 93 & 73 & 1210 \\
\hline $1,0<\mathrm{RFP}<=1,5$ & 14 & 217 & 0 & 190 & 31 & 72 & 524 \\
\hline $1,5<\mathrm{RFP}<=2,5$ & 22 & 388 & 0 & 313 & 50 & 48 & 821 \\
\hline $2,5<\mathrm{RFP}<=3,5$ & 19 & 170 & 0 & 127 & 14 & 27 & 357 \\
\hline $\mathrm{RFP}>3,5$ & 22 & 398 & 0 & 196 & 37 & 15 & 668 \\
\hline Não declarada & 24 & 525 & 1 & 433 & 75 & 287 & 1345 \\
\hline
\end{tabular}

Fonte: Adaptação PNP. Elaboração própria, ${ }^{3} 2020$.

A questão da autodeclaração racial como critério a priori de identificação para o ingresso nas universidades e instituições federais está prevista na Lei n. 12.711 (BRASIL, 2012). O artigo $1^{\circ}$ trata da reserva de $50 \%$ das vagas para estudantes com renda igual ou inferior a 1,5 salário mínimo per capita de cada processo seletivo em cursos de graduação para egressos do Ensino Médio que tenham concluído integralmente essa etapa do ensino em escolas públicas. $\mathrm{O}$ artigo $3^{\circ}$ esclarece a contribuição racial da lei no âmbito nacional.

Art. $3^{\circ}$. Em cada instituição federal de ensino superior, as vagas de que trata $o$ art. $1^{\circ}$ desta Lei serão preenchidas, por curso e turno, por autodeclarados pretos, pardos e indígenas e por pessoas com deficiência, nos termos da legislação, em proporção ao total de vagas no mínimo igual à proporção respectiva de pretos, pardos, indígenas e pessoas com deficiência na população da unidade da Federação onde está instalada a instituição, segundo o último censo da Fundação Instituto Brasileiro de Geografia e Estatística - IBGE (BRASIL, 2016).

Considerando a renda familiar dos discentes é esperada a eficiência das Ações Afirmativas no que diz respeito à admissão dos estudantes pretos, pardos e indígenas cefetianos. Os indígenas matriculados podem ter sido admitidos na instituição pela política de cotas em sua totalidade, assim como um maior número de pretos e pardos que declararam renda familiar de até 1,5 salários mínimos, percentuais superiores a 67\% e 61\%, respectivamente. Os amarelos que declararam renda similar foram de 60,88\%, e os autodeclarados brancos, $30,24 \%$.

Osório nos diz que "conhecendo a renda dos pais é possível prever com acuidade a renda dos filhos" (2009, p. 322), uma tendência de reprodução entre a origem do egresso e o seu destino social. Na contemporaneidade, a distribuição de renda de um indivíduo branco ou não branco "não é muito distante da que ocupavam no passado, quando sua renda era determinada pela do grupo doméstico de origem" (OSÓRIO, 2009).

Buscando uma correção para esse horizonte, Osório considera que,

[p]ara que a desigualdade racial de renda diminuísse, seria preciso que a mobilidade dos negros fosse predominantemente ascendente e a dos brancos descendente. Em uma redução gradual, os regimes de mobilidade começariam bem distintos e iriam se assemelhando até se tornarem, após equalização racial, idênticos (2009, p. 323). 
É sabido “que a proporção de jovens que se definem como 'pardos' e 'pretos' nas universidades brasileiras, principalmente naquelas que são públicas e gratuitas, está muito abaixo da proporção desses grupos de cor na população" (GUIMARÃES, 2003, p. 256). Ao analisar a proporção de negros nos cursos de engenharia do CEFET-MG, o percentual de estudantes brancos é superior, podendo apresentar uma supremacia branca em determinados cursos de graduação. Ademais, o público alocado no Grupo II, por sua vez, seria composto dos indivíduos negros que provavelmente não passaram por desconfortos de ordem socioeconômica durante seus percursos educacionais (GUIMARÃES, 2003). Seriam eles os possíveis herdeiros de famílias mais escolarizadas, das classes média e alta, ambas desejosas de uma formação superior com garantia de maior status, possibilidade de retorno financeiro satisfatório e chances reais de alcançarem níveis mais elevados dentro da estrutura educacional. Ainda assim, negros.

Sobre a cor, Jessé Souza (2005) afirma que, "no caso brasileiro, 'a cor da pele’ é um dado secundário em relação ao habitus de classe" (LIMA, 2012, p. 247), de modo que os "pardos" teriam acesso a uma possibilidade de fuga da classificação de negro. No entanto, o gozo dessa fuga dependerá da posição socioeconômica do sujeito autodeclarado pardo.

Em termos conceituais, a "saída de emergência” refere-se à noção de que, por meio de ascensão no status social ou do branqueamento intergeracional, os indivíduos pardos passam a gozar de certos benefícios que não seriam estendidos aos pretos. Daniel (2006) complementa esta noção afirmando que a "saída de emergência" é uma espécie de controle social de acesso a categorias intermediárias de cor (PORTO; FUKS; MUNIZ, 2016, p. 6).

Esta "saída de emergência" para o sujeito pardo garantiria possibilidades de mobilidade dentro da estrutura social, superando a rigidez racial das ocupações (OSÓRIO, 2004; SANTOS, 2005; RIBEIRO, 2009; LIMA, 2012).

De certo que, em época específica da História, o povo negro permaneceu em um lugar subalterno dentro da estrutura de produção e distribuição do capital, sinalizando para a existência e a persistência do racismo como parte de uma estrutura desigual de oportunidades, presente nas relações capitalistas, ideológica e politicamente associada à formação e qualificação desse grupo étnico (HASENBALG, 2005). Essa estrutura se apresenta nos mais variados tons de pele, do preto ao "pardo mais clarindo". Com a miscigenação, foram geradas as variações de tom de pele e, dessas variações, as diferenciações entre pessoas de um mesmo grupo racializado, segundo as quais aquele que se apresentar com aparência mais próxima da população europeia poderá usufruir de privilégios sociais.

Ser negro ou estudante negro no Brasil não se resume apenas à cor autodeclarada. Há uma composição de fatores observados e reafirmados durante os recentes processos realizados pelas bancas de verificação racial, indo desde textura dos cabelos, formato dos lábios, nariz e demais traços e comportamentos sociais discriminatórios que justifiquem a contemplação dos pretos e pardos em Ações Afirmativas raciais, permitindo pleitear o status de cotistas.

Iniciado o sistema de cotas no CEFET-MG, no ano de 2013, após a implementação da Lei n. 12.711, em 29 de agosto de 2012, cujo gozo à reserva de vagas depende da condição de negro(a) do sujeito, revelou-se a necessidade do reconhecimento e da autoafirmação dos estudantes como cidadãos pertencentes ao grupo étnico-racial em questão. Joaquim Barbosa Gomes define as Ações Afirmativas como

[...] um conjunto de políticas públicas e privadas de caráter compulsório, facultativo ou voluntário, concebidas com vistas ao combate à discriminação racial, de gênero, por deficiência física e de origem nacional, bem como para corrigir ou mitigar os efeitos presentes da 
discriminação praticada no passado, tendo por objetivo a concretização do ideal de efetiva igualdade de acesso a bens fundamentais como a educação e o emprego (2003, p. 53).

As cotas raciais e demais Ações Afirmativas implementadas nas instituições em todo país são ações que visam obter justiça contra iniquidades raciais persistentes na sociedade brasileira, devendo, portanto, ser destinadas às "potenciais vítimas diretas do racismo e da discriminação racial" de modo que, dentro de um contexto sociorracial, possam ser decisivas para a formação e o reconhecimento de uma identidade étnica nacional (VAZ, 2018, p. 40).

O critério utilizado pelas instituições como forma de verificação racial do candidato às vagas nas universidades e institutos federais "deve ser, exclusivamente, o fenótipo do próprio indivíduo", de forma que o mesmo fator que o exclua seja o que o integre como "destinatário das Ações Afirmativas de cunho racial" (VAZ, 2018, p. 39-40).

No que diz respeito às Ações Afirmativas em concursos públicos, foram definidos aparatos legais para a seleção de pessoas negras, conforme preconiza a Lei n. 12.990 .

Art. $2^{\circ}$. Poderão concorrer às vagas reservadas a candidatos negros aqueles que se autodeclararem pretos ou pardos no ato da inscrição no concurso público, conforme o quesito cor ou raça utilizado pela Fundação Instituto Brasileiro de Geografia e Estatística - IBGE.

Parágrafo único. Na hipótese de constatação de declaração falsa, o candidato será eliminado do concurso e, se houver sido nomeado, ficará sujeito à anulação da sua admissão ao serviço ou emprego público, após procedimento administrativo em que lhe sejam assegurados o contraditório e a ampla defesa, sem prejuízo de outras sanções cabíveis (BRASIL, 2014).

A efetiva incorporação da identidade negra parece responder, então, a um duplo desejo: o desejo da singularidade e, concomitantemente, a necessidade de participação do indivíduo em todo e qualquer modelo considerado positivo para esse grupo (FELSON, 1993; SANTOS, 2005).

\section{Considerações Finais}

Com base nos dados discutidos neste artigo, concluímos que as pessoas negras que objetivaram a formação em engenharia no ano de 2017, no CEFET-MG, equivalem a um número reduzido entre os estudantes da instituição. Mesmo com a implementação da Lei de Cotas, ainda existem desigualdades no que se refere à profissão engenheiro. Mais do que isso, os dados apresentados parecem sugerir que, apesar da formação acadêmica e da atuação no mercado de trabalho, haveria uma tendência de reprodução da desigualdade de renda entre os profissionais do mesmo grupo étnico-racial.

Realizou-se aqui um estudo exploratório baseado em fontes documentais e bibliográficas, passível de ser reproduzido em pesquisas de programas educacionais para averiguação do padrão racial vigente nos diferentes cursos de graduação de universidades públicas e privadas do território nacional. Análises mais recentes, dados que abrangem informações sobre a estratégia das famílias para educação dos filhos ou, ainda, estudos sobre os distintos níveis de pós-graduação possivelmente trariam luz a outros aspectos não observados neste artigo.

Reconhecendo essa limitação, cremos que o estudo permitiu ilustrar a prevalência de estudantes autodeclarados brancos nas engenharias do CEFET-MG, independentemente do campus analisado. Esperamos 
contribuir para o despertar da necessidade de implementação, aperfeiçoamento e perpetuação das Políticas de Ação Afirmativa no país, com o objetivo de equalizar as oportunidades educacionais e profissionais de estudantes.

\section{Contribuições das Autoras}

Problematização e Conceituação: Valentim SS; Silva RC; Metodologia: Silva RC; Valentim SS; Análise: Silva RC; Valentim SS; Redação: Silva RC; Valentim SS.

\section{Notas}

1. Informações retiradas do site institucional do CEFET-MG.

2. Com base nos dados da pesquisa documental.

3. Planilha adaptada da Plataforma Nilo Peçanha. Baseada nos dados da pesquisa documental sobre a Classificação Racial e Renda Familiar dos discentes do CEFET-MG - ano 2019.

\section{Referências}

ALMEIDA, W. M. ProUni e o Ensino Superior privado lucrativo em São Paulo: uma análise sociológica. São Paulo: Musa/FAPESP, 2014.

ALMEIDA, W. M. ProUni e o acesso de estudantes negros ao Ensino Superior. Revista Contemporânea de Educação. Rio de Janeiro, v. 12, n. 23, p. 89-105, 2017. https://doi.org/10.20500/rce.v12i23

ANDIFES [ASSOCIAÇÃO NACIONAL DOS DIRIGENTES DAS INSTITUIÇÕES FEDERAIS DE ENSINO SUPERIOR]. IV Perfil Socioeconômico e Cultural dos Estudantes da Graduação das Instituições Federais de Ensino Superior Brasileiras. Uberlândia: Andifes, 2016. Disponível em: https://www.andifes. org.br/wp-content/uploads/2021/07/IV-Pesquisa-Nacional-de-Perfil-Socioeconomico-e-Cultural-dos-asGraduandos-as-das-IFES.pdf. Acesso em: 12 set. 2018.

ANDRIOLA, W. B. Doze motivos favoráveis à adoção do Exame Nacional do Ensino Médio (Enem) pelas Instituições Federais de Ensino Superior (IFES). Ensaio: Avaliação de Políticas Públicas em Educação, Rio de Janeiro, v. 19, n. 70, p 107-126, 2011. https://doi.org/10.1590/S0104-40362011000100007

BABBIE, E. Métodos de pesquisa de survey. Tradução Guilherme Cezarino. Belo Horizonte: Ed. UFMG, 2003. BORGES, J. L. G.; CARNIELLI, B. L. Educação e estratificação social no acesso à universidade pública. Cadernos de Pesquisa, São Paulo, v. 35, n. 124, 2005. https://doi.org/10.1590/S0100-15742005000100007

BOURDIEU, P. Escritos de educação. Petrópolis: Vozes, 1998.

BRASIL. Lei n. 12.711, de 29 de agosto de 2012. Dispõe sobre o ingresso nas universidades federais e nas instituições federais de ensino técnico de nível médio e dá outras providências. Diário Oficial da União, 
Brasília, DF, 30 ago. 2012. Disponível em: http://www.planalto.gov.br/ccivil_03/_ato2011-2014/202/lei/ 112711.htm. Acesso em: 27 ago. 2018.

BRASIL. Lei n. 12.990, de 9 de junho de 2014. Reserva aos negros 20\% (vinte por cento) das vagas oferecidas nos concursos públicos para provimento de cargos efetivos e empregos públicos no âmbito da administração pública federal, das autarquias, das fundações públicas, das empresas públicas e das sociedades de economia mista controladas pela União. Diário Oficial da União, Brasília, DF, 10 jun. 2014. Disponível em: http:// www.planalto.gov.br/ccivil_03/_ato2011-2014/2014/lei/112990.htm. Acesso em: 27 ago. 2018.

BRASIL. Lei n. 13.409, de 28 de dezembro de 2016. Altera a Lei n. 12.711, de 29 de agosto de 2012, para dispor sobre a reserva de vagas para pessoas com deficiência nos cursos técnicos de nível médio e superior das instituições federais de ensino. Diário Oficial da União, Brasília, 29 dez. 2016. Disponível em: http:// www.planalto.gov.br/ccivil_03/_ato2015-2018/2016/lei/13409.htm. Acesso em: 25 ago. 2018.

CEFET-MG. Secretaria de Política Estudantil. Belo Horizonte: SPE, 2013. Disponível em: http://www.spe. cefetmg.br/2013/07/19/pesquisa-sipe-brasil-traca-perfil-dos-estudantes-de-graduacao-das-ifes/. Acesso em: 10 abr. 2020.

COMIN, A. A.; BARBOSA, R. J. Trabalhar para estudar: sobre a pertinência da noção de transição escolatrabalho no Brasil. Novos Estudos Cebrap, São Paulo, v. 91, p. 75-95, 2011. https://doi.org/10.1590/ S0101-33002011000300004

FELSON, R. B. The (somewhat) social self: how others affect self-appraisals. In: SULS, J. (ed.). Psychological perspective on the self. Illsdale: Lawrence Erlbaum, 1993. v. 4.

FIALHO, F. B. Mobilização parental e excelência escolar: um estudo das práticas educativas de famílias das classes médias. 2012. 123 f. Dissertação (Mestrado em Educação) - Faculdade de Educação, Universidade Federal de Minas Gerais, Belo Horizonte, 2012.

FUNDAÇÃO CEFET-MG. Cerimônia Olímpica abre os Jogos das Instituições Federais. Belo Horizonte: FCM, 2018. Disponível em: http://fundacaocefetminas.org.br/2018/08/22/cerimonia-olimpica-abre-jogosdas-instituicoes-federais-no-cefet-mg/. Acesso em: 26 ago. 2018.

GOMES, J. B. B. O debate constitucional sobre Ações Afirmativas. In: Ação Afirmativa - políticas públicas contra as desigualdades raciais. SANTOS, R. E.; LOBATO, F. (orgs.). Rio de Janeiro: DP\&A, 2003, p. 15-57.

GRINSPUN, M. P. S. Z. A orientação educacional: conflito de paradigmas e alternativas para a escola. São Paulo: Cortez, 2002.

GUERRA, A. et al. Atlas da nova estratificação social no Brasil: classe média desenvolvimento e crise. São Paulo: Cortez, 2006.

GUIMARÃES, A. S. A. Acesso de negros às universidades públicas. Cadernos de Pesquisa, São Paulo, n. 118, p. 247-268, 2003. https://doi.org/10.1590/S0100-15742003000100010

HASENBALG, C. A. Discriminação e desigualdades raciais no Brasil. 2. ed. Belo Horizonte/Rio de Janeiro: Ed. UFMG/IUPERJ, 2005.

IBGE [INSTITUTO BRASILEIRO DE GEOGRAFIA E ESTATÍSTICA]. Censo Demográfico 2010. Brasília, DF: IBGE, 2010. Disponível em: http://censo2010.ibge.gov.br/. Acesso em: 20 nov. 2018. 
LIMA, M. "Raça” e pobreza em contextos metropolitanos. Tempo Social, São Paulo, v. 24, n. 2, p. 233-254, 2012. https://doi.org/10.1590/S0103-20702012000200012

MUNANGA, K. As facetas de um racismo silencioso. In: SCHWARCZ, L. M.; QUEIROZ, R. S. (orgs.). Raça e diversidade. São Paulo: EDUSP, 1996.

NICODEMOS, P. A. Sobre construções identitárias de adolescentes negros de classe média: um estudo de caso em uma escola particular de Belo Horizonte - MG. 2011. Dissertação (Mestrado em Educação) Programa de Pós-graduação em Educação, Pontifícia Universidade Católica de Minas Gerais, Belo Horizonte, 2011.

NICODEMOS, P. A. 2016. Retratos socioantropológicos de jovens negros de elite, estudantes do Ensino Superior em Belo Horizonte - MG - BRASIL: trajetórias, projetos de vida e sociabilidades. 2016. Tese (Doutorado em Educação) - Programa de Pós-graduação em Educação da Pontifícia Universidade Católica de Minas Gerais, Belo Horizonte, 2016.

OSÓRIO, R. G. A mobilidade social dos negros brasileiros. Brasília, DF: IPEA, 2004. Disponível em: https:// www.ipea.gov.br/portal/images/stories/PDFs/TDs/td_1033.pdf. Acesso em: 5 mar. 2021.

OSÓRIO, R. G. A desigualdade racial de renda no Brasil: 1976-2006. 2009. 362 f. Tese (Doutorado em Sociologia) - Instituto de Ciências Sociais, Universidade de Brasília, Brasília, 2009.

PICANÇO, F.; MORAIS, J. Estudos sobre estratificação educacional: síntese dos principais argumentos e desdobramentos. Educação \& Sociedade, Campinas, v. 37, n. 135, p. 391-406, 2016. https://doi.org/10.1590/ ES0101-73302016126201

PLATAFORMA NILO PEÇANHA. PNP 2020. Brasília, DF: MEC, 2020. Disponível em: http:// plataformanilopecanha.mec.gov.br/2020.html. Acesso em: 24 jul. 2021.

PORTO, N. F. F.; FUKS, M.; MUNIZ, J. O. Nem tão "preto e branco": explicando as atitudes dos pardos no Brasil. In: ENCONTRO ANUAL DA ANPOCS, 40., 2016, Caxambu. Anais [...] Caxambu, 2016. Disponível em: https:/www.anpocs.com/index.php/papers-40-encontro/st-10/st06-8/10186-nem-tao-preto-e-brancoexplicando-as-atitudes-dos-pardos-no-brasil/file. Acesso em: 6 maio 2020.

QUADROS, W. J. A evolução recente das classes sociais no Brasil. In: PRONI, M. W.; HENRIQUE, W. (orgs.). Trabalho, mercado e sociedade: o Brasil dos anos 90. São Paulo/Campinas: Editora UNESP/Instituto de Economia da Unicamp, 2003.

RIBEIRO, C. A. C. Desigualdades de oportunidades no Brasil. Belo Horizonte: Argvmentvm, 2009.

RIBEIRO, C. A. C. Raça, classe e mobilidade social no Brasil. Dados - Revista de Ciências Sociais, Rio de Janeiro, v. 49, n. 4, 2007, p. 833-873. https://doi.org/10.1590/S0011-52582006000400006

RIBEIRO, C. A. C.; SCHLEGEL, R. Estratificação horizontal da educação superior no Brasil (1960 a 2010). In: ARRETCHE, M. T. S. (org.). Trajetórias das desigualdades: como o Brasil mudou nos últimos cinquenta anos. São Paulo: Unesp, 2015. p. 133-162.

SANTOS, C. A construção social do conceito de identidade profissional. Interacções, Coimbra, n. 8, p. 123144, 2005. Disponível em: https://interacoes-ismt.com/index.php/revista/article/view/145. Acesso em: 9 jun. 2019. 
SANTOS, J. A. F. Efeitos de classe na desigualdade racial no Brasil. DADOS - Revista de Ciências Sociais, Rio de Janeiro, v. 48, n. 1, p. 21-45, 2005. https://doi.org/10.1590/S0011-52582005000100003

SILVA, N. V. Expansão escolar e estratificação educacional no Brasil. [U4] In: HASENBALG, C. A.; SILVA, N. V. (orgs.). Origens e destinos: desigualdades sociais ao longo da vida. Rio de Janeiro: Topbooks, 2003. p. $105-146$.

SOTERO, E. C. Negros no Ensino Superior: trajetórias e expectativas de estudantes de administração beneficiados por Políticas de Ação Afirmativa (ProUni e Cotas) em Salvador. 2009. 138 f. Dissertação (Mestrado em Sociologia) - Faculdade de Filosofia, Letras e Ciências Humanas, Universidade de São Paulo. São Paulo, 2009.

SOUZA, J. Raça ou classe? Sobre a desigualdade brasileira. São Paulo: Lua Nova, n. 65, 2005. p. 43-69.

STAVENHAGEN, R. Estratificação social e estrutura de classe. In: VELHO, O. G. C. A.; PALMEIRA, M. G. S.; BERTELLI, A. R. (orgs.). Estrutura de classes e estratificação social. 7. ed. Rio de Janeiro: Zahar, 1977.

VAZ, L. M. S. S. As comissões de verificação e o direito à (dever de) proteção contra a falsidade de autodeclarações raciais. In: DIAS, G. R. M.; TAVARES JÚNIOR, P. R. F. (orgs.). Heteroidentificação e cotas raciais: dúvidas, metodologias e procedimentos. Canoas: IFRS, 2018. p. 32-78.

\section{Sobre as Autoras}

Regiane Cristina da Silva é graduada em Física pela Universidade de Franca (2020) e bacharel em Engenharia Civil pelo Centro Universitário Metodista Izabela Hendrix (2015). Atualmente é discente da Especialização em Ensino e Tecnologias Educacionais (IFMG São João Evangelista) e Mestranda em Educação Tecnológica no Centro Federal de Educação Tecnológica de Minas Gerais. Tem experiência no ensino de Física e Educação, com ênfase na educação básica. Na educação superior vem atuando principalmente nos seguintes temas: egressos negros; engenharias; afrodescendentes e engenharia.

Silvani dos Santos Valentim é professora do Centro Federal de Educação Tecnológica de Minas Gerais e docente permanente do Programa de Pós-Graduação em Educação Tecnológica, do Departamento de Educação e do Programa Especial de Formação Docente. Coordena a Coordenadoria de Gênero, Raça, Ações Afirmativas e Identidades (CGRAI/CEFET-MG) e é líder do Núcleo de Pesquisa e Estudos Afro-Brasileiros (NEAB/CEFET-MG). Coordena os projetos Afrociências - Popularização do Conhecimento Científico (CNPq) e Afrocientista (ABPN/Fundação Unibanco). É Secretária Executiva da Associação Brasileira de Pesquisadores(as) Negros(as) e integra o comitê científico do GT 21 da Associação Nacional de Pós-graduação e Pesquisa em Educação.

Recebido: 31 jul. 2021 